\section{COVID-19 RESPONSE IN A RESEARCH HOSPITAL}

Lorraine Hodsdon, Grant Nicholson, Vanshree Patel, Jenny Rivers. Great Ormond Street Hospital

\subsection{6/archdischild-2020-gosh.98}

Introduction This abstract outlines the actions that were taken as part of the R\&I response to the first COVID-19 surge.

Research Activity As a Research Hospital, many of our trials provide essential treatment for children. These were identified using defined criteria; activity continued on $20 \%$ of our clinical trials (60/300), both on-site and delivering care remotely. This involved many regulatory and contract amendments which stood us in good stead as we developed a new way of working.

COVID-19 Research The R\&D office received 68 requests for COVID-19 related project registrations. 13 approvals have been granted so far. Projects addressing the health, social, economic, cultural and environmental impacts of the COVID-19 outbreak. Much COVID-19 research is classified as Urgent Public Health https://www.nihr.ac.uk/covid-19/ with the expectation that the Trust will take on these projects.

Staff Redeployment From late March to mid-July, both clinical and non-clinical staff were redeployed across the organisation to provide additional support needed for frontline clinical care and vital operations.

This was managed successfully resulting in re-deployment of $33 \%$ of R\&I staff (total headcount 130 staff, redeployment represents $55 \%$ of nursing workforce) to provide frontline support for COVID-19.

Restart From mid-May 2020, the research portfolio has been reviewed and capacity and capability of all departments assessed. Where appropriate final sign off for restart given by Head of Clinical Research Operations and Head of Governance, Clinical Trials and Contracts.

All studies are under review to restart, with 21 already approved and a number of new studies in the pipeline. Priority assessment is being driven by clinical teams as well as the research delivery teams.

Conclusion Staffing priorities were managed in order to enable R\&I to continue delivering essential research whilst prioritising COVID-19 research and providing operational and clinical resource across the organisation to support the additional Trust COVID-19 related activity.

\section{CREATING VIRTUAL LEARNING SERIES TO BUILD AN UNDERSTANDING OF QUALITY IMPROVEMENT TRUST WIDE}

Karleen Huggins, Rhiannon Follett, Nuwanthi Yapa Mahathanthila. Great Ormond Street Hospital

\subsection{6/archdischild-2020-gosh.99}

Background The Quality Improvement (QI) team facilitates a range of face to face foundation courses which are self-elected and available to all staff across the Trust. The impact of COVID has encouraged the team to think about different ways to deliver this training. The aim of the project was to build a virtual learning series to allow the team to continue to build sustainable understanding of QI Trust-wide

Method The existing content was refreshed from 4 core 90 minute courses to a 6 part series. The target audience was anyone new to QI or those that have some involvement in a
QI project. The series runs for an hour over 6 consecutive weeks, offering a foundation understanding of QI methodology and the tools required to run a QI project.

The course would be delivered via Zoom, presenting from PowerPoint and the team sourced an external tool (Mentimeter) to allow for some interactive exercises during the sessions.

Optional advanced courses and project surgeries are also available to support participants with their QI projects and learning.

The QI Team implemented PDSA cycles (QI Tool) and Evaluation Surveys to improve the delivery of the series.

*Ethical approval not required

Results The series was promoted Trust-wide resulting in registration exceeding recent face to face enrolment.

There was a steady commitment from Cohort 1, feedback has been positive and the additional QI surgeries have also been well received.

Discussion The consistent attendance has confirmed that reducing the course length and conducting the series during the lunch period has resulted in a wider reach across the Trust. It also demonstrates that teams can attend to work on a joint QI project.

Conclusion Through the creation of a virtual learning series, the QI team have been able to continue to build sustainable understanding of QI Trust-wide.

\section{$100 \quad$ SOCIALLY DISTANT BUT CLOSER THAN EVER}

Cathy Roberts.

\subsection{6/archdischild-2020-gosh.100}

The Children's Acute Transport service (CATS) is a standalone paediatric critical care transport service with a small core team of 12 nurses. With COVID restrictions limiting the number of personnel in office, staff deployed to other services, there were less opportunities to work and socialise together.

A session in an a training day allowed time for everyone to share their experience of the pandemic so far. Staff gained insight into each others experiences, and anxieties, and were able to re-connect as a team. To promote wellbeing, external speakers were engaged to provide training on stress, self care, and psychological PPE which will form part of our annual updates.

\section{1 COVID PROOFING A PAEDIATRIC INTENSIVE CARE TRANSPORT SERVICE}

${ }^{1}$ Cathy Roberts, ${ }^{2}$ Mark Clement, ${ }^{3}$ Maeve O'Connor. ${ }^{1}$ Cathy Roberts; ${ }^{2}$ Children's Acute Transport Service (CATS); ${ }^{3}$ Children's Acute Transport Service

\subsection{6/archdischild-2020-gosh.101}

The Children's Acute Transport service (CATS) is a standalone paediatric critical care transport service in the North Thames and East Anglia region. In February 2020, it became evident we would be involved in the inter hospital transfer of potential and confirmed Covid positive patients, necessitating the rapid generation of a plan to examine our process and recalibrate for the pandemic. 